\title{
The effects of anti-sense interleukin-5 gene transferred by recombinant adeno-associated virus in allergic rats
}

Daxiong Zeng", Yong Cao ${ }^{*}$, Qingfeng Song, Chao Cao, Xiansheng Liu, Yongjian Xu and Weining Xiong ${ }^{+}$

Department of Respiratory Medicine, Tongji Hospital, Key laboratory of Pulmonary diseases of Ministry of health of China, Tongji Medical College, Huazhong University of Science and Technology, Wuhan 430030, P. R. China.

This work was supported by the National Natural Science Foundation of China (No. 30300144).

*These authors contributed equally to this study.

+ Correspondence and requests for reprints should be addressed to Weining Xiong, PH.D., Department of Respiratory Medicine, Tongji Hospital, Key laboratory of Pulmonary diseases of Ministry of health of China, Tongji Medical College, Huazhong University of Science and Technology, Wuhan 430030, P. R. China. E-mail: xiongweining@tjmu.tjh.edu.cn. 


\begin{abstract}
The accumulation and infiltration of eosinophils in airways is one of the most important characteristics of asthma, and is mediated partly by secretion of IL-5 from Th2 lymphocytes. It is well known that interleukin-5 (IL-5) played an important role in the regulation of eosinophils. In this study, an anti-sense IL-5 gene transferred by recombinant adeno-associated virus (rAAV-ASIL-5) was prepared to transfect allergic rats. It was found that the expression of IL-5 protein in plasma and BALF were inhibited significantly. The rAAV-ASIL-5-mediated suppression of total cell counts in peripheral blood and BALF were also observed. Moreover, rAAV-ASIL-5 remarkably reduced the eosinophil counts in peripheral blood and BALF, as well as the expression of ECP protein in plasma and BALF. The inflammation in lungs of rAAV-ASIL-5 pretreated rats also became slighter when compared with allergic rats. Otherwise, no apparent pathological damage to vital organs of rats was found. In conclusion, recombinant adeno-associated virus-mediated delivery of anti-sense IL-5 gene inhibited the accumulation of eosinophils and the airways inflammation in rat model of allergic asthma via suppressing IL-5 expression. It suggested the feasibility of rAAV-ASIL-5 in the gene therapy for allergic asthma and other eosinophilic diseases.
\end{abstract}

Keywords: adeno-associated virus, interleukin-5, asthma, gene therapy 


\section{Introduction}

Asthma is a complex chronic inflammation disease of airways which is characterized by reversible airway obstruction, bronchial hyper-reactivity and airway inflammation with eosinophils, mast cells and $\mathrm{T}$ lymphocytes infiltration (1). Eosinophil is thought to be major effecter cell in the inflammation process of asthma. The accumulation and infiltration of airways eosinophils is one of the most important characteristics of asthma (2). There is a strong association between airways eosinophils inflammation and the development of lung pathology in asthma. Activated eosinophils can release oxygen free radicals and toxic granule proteins, such as eosinophil cationic protein (ECP), major basic protein (MBP), eosinophil protein $\mathrm{X} /$ eosinophil derived neurotoxin (EPX/EDN) and eosinophil peroxidase (EPO). ECP and MBP are highly cationic proteins with a number of biological activities of which the cytotoxic potency of the protein is more conspicuous. They may be assayed in most biological fluids as markers of eosinophil activity and turnover. EPO produces hypophalous acid capable of killing parasites by oxidizing halides (3). In addition, activated eosinophils can also generate membrane derived lipid mediators, for instance platelet-activating factor (PAF) and leukotriene-C4 (LTC4), as well as reactive oxygen species that may add to their proinflammatory effects $(4,5)$. Eosinophils inflammation is considered as one of the most important contributors to the structural and functional changes in airways of asthma, including bronchial hyper-reactivity, damage to epithelial cells, hyperplasia of goblet cells, hypertrophy of the airway smooth muscle cells and fibrosis $(6,7)$. The presence of eosinophils and their products in airways are recognized contributors to the disease severity and the development of airway hyper-reactivity in asthma $(3,8)$.

Interleukin-5 (IL-5) is mainly produced by activated Th2 cells, a sort of CD4 ${ }^{+} \mathrm{T}$ lymphocytes. It has been long established that IL-5 is vital in promoting eosinophils proliferation, differentiation and survival (9). Previous researches revealed that IL-5 is one of the most critical regulatory factors of eosinophils $(10,11)$. IL-5 play an important role in activating eosinophils, preventing eosinophils apoptosis, inducing eosinophils precursor cells differentiation, and encouraging toxic granule proteins and 
inflammation mediators secreting from eosinophils $(12,13)$. Furthermore, IL-5 has the functions of gathering eosinophils, reinforcing antigen-inducing eosinophils degranulation reaction, and enhancing antibody-dependent cytotoxic effect (14). Therefore, as a sort of representative cytokine produced from overplenty Th2 cells in asthma, IL-5 may act a vital role in the development of asthma. The suppression of IL-5 is theoretically beneficial to therapy for asthma.

Preceding researches revealed that anti-IL-5 therapy could suppress the airway inflammation and hyper-reactivity in asthmatic mice. Eosinophils and airways hyper-reactivity to inhaled methacholine did not develop in OVA sensitized and challenged IL-5-deficient BALB/c mice (15). An anti-sense oligonucleotide of IL-5 significantly inhibited eosinophils in vivo, coincided with specifically reduce of IL-5 protein level in both the murine OVA challenged and allergic peritonitis models (16). The treatment of anti-IL-5 antibody also had remarkable anti-inflammation effects on OVA sensitized and challenged BALB/c mice, including decreasing the numbers of both intraepithelial eosinophils and chronic inflammatory cells in the airway wall, inhibiting the development of subepithelial fibrosis et al (17). Many clinic studies (18-20) also manifested that anti-IL-5 therapy inhibited the expression of IL-5 and prevented eosinophils accumulation in vivo.

Although the therapy of asthma with anti-IL-5 monoclonal antibody is beneficial and feasible, there are still some questions which restricted the widely application of anti-IL-5 monoclonal antibody, such as the problems of immunity reaction and persistent effect. Moreover, anti-IL-5 monoclonal antibody only inhibited IL-5 protein which had been excreted, but not fundamentally reduced the potential synthesis of IL-5. New methods should be investigated for a more stable and long-term treating effect on the development of asthma.

Following with the rapid development of molecular biology, we could integrate the objective gene in chromatosome via the technology of gene interfere, for instance the virus vector mediated delivery. Several viral vectors, including lentivirus, adenovirus, rAAV and other viral vectors can be adaptive for gene therapy of genetic or chronic diseases. The rAAV vector, which either integrates into the genome or remains in the 
nucleus as a stable episome, offers attractive advantages and may be one of the most promising gene vector for long-term therapy (21). The AAV has many advantages and properties compared with other vectors, such as the lack of inflammatory response, the ability to infect the dividing and non-dividing cells, especially including $\mathrm{T}$ lymphocytes $(22,23)$. The AAV is safe to use because of not producing viral proteins that stimulate inflammatory reactions and not replicating inside cells without the presence of a wild-type adenovirus $(24,25)$. The AAV is effective as a vector as it contains sufficient carrying capacity for the insertion of many sorts of exogenous genes. As a result, it is possible for exogenous gene to produce a sustained and marked effect through persistent expression $(26,27)$. In this way, finding a long-term treatment method could become easier.

In our past research (28), we found that a rAAV-ASIL-5 suppressed the expression of IL-5 mRNA and protein in $\mathrm{CD}_{4}^{+} \mathrm{T}$ lymphocytes of allergic asthmatic rat model in vitro. On this base, aiming to observe the effect of rAAV-ASIL-5 on allergic rat in vivo, we constructed a kind of novel rAAV vector which may mediate a persistent anti-sense IL-5 gene expression, and then transfected allergic rats with it through tail vein. 


\section{Materials and Methods}

\section{Construction of plasmid pSNAV-ASIL-5 and pSNAV-EGFP}

Vector plasmid pSNAV (29) was bought from Vector Gene Technology Co. Ltd. (China). The genome of plasmid pSNAV contained inverted terminal repeats (ITR) of rAAV and cytomegalovirus immediate early (CMV IE) promoter followed by a multiple clone site (MCS). The MCS included several sites of restriction enzyme, such as NotI and EcoRV et al. A plasmid pASIL-5 which containing the anti-sense IL-5 gene was constructed previously (28). Fragment which contained the complete cDNA of rat IL-5 gene was obtained from the plasmid pASIL-5. Then it was inserted into the pSNAV-X vector in the anti-sense orientation between the restriction enzyme sites of EcoRV and NotI. It was named plasmid pSNAV-ASIL-5, which was following identified by sequencing in Shanghai Bioengineering Co. Ltd. (China). The genome of the recombinant pSNAV-ASIL-5 contained inverted terminal repeats of rAAV and CMV promoter and enhancer followed by anti-sense IL-5 cDNA and SV40 polyA. Plasmid pSNAV-EGFP was constructed as the same methods.

\section{Preparation of rAAV-ASIL-5 and rAAV-EGFP}

BHK-21 cells (ATCC, USA) were transfected with the recombinant plasmid pSNAV-ASIL-5 by Lipofectamine 2000 reagent (Invitrogen, USA). After 24 hours, the cell lines carrying pSNAV-ASIL-5 stably were obtained through G418 selection (neomycin, $800 \mu \mathrm{g} / \mathrm{ml}$ ) (Gibco, USA). These cell lines were plated onto a $15-\mathrm{cm}$-diameter dish and then incubated at $37^{\circ} \mathrm{C}$ in $5 \% \mathrm{CO}_{2}$. When it reached $90 \%$ of the dish (about $8 \times 10^{8}$ cells), the cells were infected by helper virus $\operatorname{HSV}-1(30,31)$ which containing the necessary Rep gene and Cap gene for rAAV virus replication and packaging at a multiplicity of infection (MOI) of 0.1 . After 48 hours, all the cells were removed and then a single-step gravity-flow column purification method was carried out (32). rAAV-EGFP (green fluorescence protein gene) was constructed and purified using the same methods.

The rAAV vectors were saved at $-80^{\circ} \mathrm{C}$ for later animal experiment. The titer and purity of rAAV-ASIL-5 and rAAV-EGFP were measured by Southern-Blot with a 
dig-labeled probe and sodium dodecyl sulfate polyacrylamide gel electropheresis (SDS-PAGE) respectively. The infectivity of rAAV was detected by transfection ratio of BHK-21 cells in vitro.

\section{Animals}

All animal experiments were carried out according to the guidelines of the Chinese Council on Animal Care and approved by Tongji Hospital (Tongji Medical College, Huazhong University of Science and Technology, Wuhan, China) Committees on Animal Experimentation. The research protocol was reviewed and approved by the hospital institutional review board of Tongji Hospital. Forty specific pathogen-free adult male Sprague-Dawley (SD) rats (aged 8-12 weeks and weighted 180-210g at the commencement of experimental study) were obtained from animal applying center of Tongji Medical College (Wuhan, Hubei Province, China). All of the animals were housed at room temperature with 12 hours light/dark cycles and allowed free access to normal rat chow and water ad libitum. The animals were randomly divided equally into four groups: normal control group (group N), asthmatic group (group A), rAAV-ASIL-5 treatment group (group T) and rAAV-EGFP negative control group (group C). The rat model of allergic asthma was established via the method described previously (33). Rats were sensitized with an subcutaneous injection of $1 \mathrm{ml} 0.2 \%$ (wt/vol) OVA (Grade III, Sigma, USA) complexed with 10\% (wt/vol) aluminum hydroxide at their footpad, neck, back, groin, and abdomen on Day 1. Futhermore, each animal received an intramuscular injection of $2 \times 10^{10}$ heat-killed Bacillus pertussis (Beijing Institute of Biological Products, China). Two weeks after the sensitization, the rats inhaled $1 \%(\mathrm{wt} / \mathrm{vol})$ OVA for 30 minutes in an exposure chamber $(50 \mathrm{~cm} \times 30 \mathrm{~cm} \times 25 \mathrm{~cm})$ to challenge their airways every other day for two weeks. The aerosol was generated with an ultrasonic nebulizer (Shanghai KODAK instrument Equipment Co. LTd. China) and was drawn into an exposure chamber containing awaked animals. The output of the nebulizer was $3 \mathrm{ml} / \mathrm{min}$ and the medium particle size was about $3.2 \mu \mathrm{m}$ according to specifications by the manufacturer. Animals in group $\mathrm{N}$ received a subcutaneous injection of $1 \mathrm{ml}$ normal saline and were 
exposed to aerosolized normal saline.

\section{Gene delivery}

Animals in group $\mathrm{T}$ and group $\mathrm{C}$ were pretreated with rAAV-ASIL-5 and rAAV-EGFP $0.5 \mathrm{ml}\left(1 \times 10^{13} \mathrm{v} . \mathrm{g} . / \mathrm{ml}\right)$ respectively on the day before sensitizing (day 0$)$ and the day before challenge (day 13) via tail vein injection. Virus vectors were replaced by normal saline in group $\mathrm{N}$ and group $\mathrm{A}$.

\section{Collecting samples}

Twenty-four hours after the last exposure to OVA or normal saline, all rats were anaesthetized by the intraperitoneal injection of $60 \mathrm{mg} / \mathrm{kg}$ pentobarbital. Animals were sterilized with $75 \%$ ethanol, fixed on operation table, opened the thoracic cavity, and draw blood from heart for cell count, extracted plasma.

After haemospasia of animal, rat right bronchus was cannulated by a tracheal cannula and lavaged with $3 \mathrm{ml}$ normal saline for bronchoalveolar lavage fluid (BALF). BALF was recovered by gentle manual aspiration with a syringe. At the same time, removed the tissues of left lung, heart, liver and left kidney to fix in $4 \%$ (wt/vol) paraformaldehyde for 24 hours.

\section{Detecting the level of IL-5 protein in plasma and BALF}

Plasma was obtained from $2 \mathrm{ml}$ blood which was centrifuged at $1000 \mathrm{rpm}$ for 10 minutes, and then saved at -80 for ELISA detection. BALF was obtained as above described and saved at -80 for ELISA detection. The level of IL-5 protein in plasma and BALF were detected by rat IL-5 ELISA kit (Rapid-bio, USA).

\section{Cell count of peripheral blood and BALF}

Cell count of peripheral blood: Added $3 \mathrm{ml}$ RBC lysis buffer to $1 \mathrm{ml}$ peripheral blood, incubated for 5 minutes, and then centrifuged at 1000rpm for 5 minutes. Cell pellet was suspended with $1 \mathrm{ml}$ normal saline. $100 \mu 1$ suspension was taken to white cell counting plate for total cells count under microscope (Nikon, Japan). At the same time, peripheral blood smears were made. Stained the blood smears with 
Wright-Giemsa solution for one minute in duplicate. Added equal buffer solution and continue stained for 10 minutes. Finally washed with water and dry it. A differential count was determined on the base of standard morphologic criteria of at least 300 cells with immersion objective microscope (34).

Cell count of BALF: The lavage fluid was centrifuged at 1000rpm for 5 minutes at $4^{\circ} \mathrm{C}$. The supernatant was saved at $-80^{\circ} \mathrm{C}$ for later detection of ELISA. The cell pellet was washed in normal saline and incubated in $1 \mathrm{ml} \mathrm{NH}_{4} \mathrm{Cl}$ for 5 minutes to remove red cells. The cell pellet was then washed twice and resuspended in $1 \mathrm{ml}$ normal saline. Total numbers of nucleated cells in BALF were determined with a cells counting plate. A differential cell count was performed by cell smears stained with Wright-Giemsa in duplicate, and was based on standard morphologic criteria of at least 300 cells with immersion objective microscope $(34,35)$.

\section{Detecting the level of ECP protein in plasma and BALF}

Plasma and BALF was obtained as above described and saved at $-80^{\circ} \mathrm{C}$ for ELISA detection. The level of ECP protein in plasma and BALF were detected by rat ELISA kit (Rapid-bio, USA) as described above.

\section{HE staining of tissues}

The removed tissues of left lung, heart, liver and left kidney were fixed in $4 \%$ (wt/vol) paraformaldehyde for 24 hours, all these tissues were embedded in paraffin and cut in $5 \mu \mathrm{m}$-thick sections. Histological changes were evaluated on sections stained with hematoxylin and eosin (HE). The pathological variations were observed under microscope.

\section{Statistical analysis}

All data were expressed as mean \pm standard deviation and analyzed by one-way ANOVA and $\mathrm{q}$ test using SPSS 12.0. A P value less than 0.05 was considered statistically significant. 


\section{Results}

\section{Effect of rAAV-ASIL-5 on expression of IL-5 protein in plasma and BALF}

As shown in Figure 1, OVA sensitization and challenge markedly increased the level of IL-5 protein in plasma and BALF when compared with normal rats $(P<0.05$ for both, group A versus group N). Treatment with rAAV-ASIL-5 significantly reduced the level of IL-5 protein in plasma and BALF $(P<0.05$ for both, group T versus group A), though they were still higher than normal rats $(P<0.05$ for both, group $\mathrm{T}$ versus group $\mathrm{N}$ ). In contrast, treatment with rAAV-EGFP had little effect on the level of IL-5 protein in plasma and BALF.

\section{Effect of rAAV-ASIL-5 on total white cells count and eosinophils count in peripheral blood}

As compared with normal rats, OVA sensitization and challenge remarkably increased the count of total white cells in peripheral blood of $(P<0.05$, group A versus group N) (Figure 2). Treatment with rAAV-ASIL-5 significantly reduced the count of total white cells in peripheral blood $(P<0.05$, group $\mathrm{T}$ versus group $\mathrm{A})$, but it was higher than normal rats $(P<0.05$, group $\mathrm{T}$ versus group $\mathrm{N})$. On the contrary, treatment with rAAV-EGFP had no effect on the total count of white cells in peripheral blood.

Eosinophils, which were seen few in the blood of normal rat, were strikingly increased in allergic rats $(P<0.05$, group A versus group $\mathrm{N})$ (Figure 2). The count of eosinophils in peripheral blood was reduced markedly with treatment of rAAV-ASIL-5 $(P<0.05$, group T versus group A), though still higher than normal rats $(P<0.05$, group $\mathrm{T}$ versus group $\mathrm{N})$. However, treatment with rAAV-EGFP had no effect on the count of eosinophils in peripheral blood.

\section{Effect of rAAV-ASIL-5 on nucleated cells count and eosinophils count in BALF}

As compared with normal rat, OVA sensitization and challenge significantly increased the count of nucleated cells in BALF $(P<0.05$, group A versus group $N)$ (Figure 2). Treatment with rAAV-ASIL-5 reduced the nucleated cells count in BALF outstandingly $(P<0.05$, group $\mathrm{T}$ versus group $\mathrm{A})$, but it was higher than normal rats $(P<0.05$, group $\mathrm{T}$ versus group $\mathrm{N})$. Contrarily, treatment with rAAV-EGFP had no 
effect on the count of nucleated cells in BALF.

Eosinophils, which were nearly absent in BALF of normal rats, were increased observably in allergic rats ( $P<0.05$, group A versus group $\mathrm{N}$ ) (Figure 3). The count of eosinophils in BALF was markedly reduced with treatment of rAAV-ASIL-5 $(P<0.05$, group T versus group A), though still higher than normal rats $(P<0.05$, group T versus group N). But treatment with rAAV-EGFP had no effect on the count of eosinophils in BALF.

\section{Effect of rAAV-ASIL-5 on expression of ECP protein in plasma and BALF}

Considering ECP as one of the crucial monitors of eosinophils in allergic asthma and other eosinophilic diseases (3), we detected the expression of ECP protein in blood and BALF to observe the anti-eosinophil effect of this novel rAAV-ASIL-5 vector. OVA sensitization and challenge markedly increased the level of ECP protein in plasma and BALF as compared with normal rats $(P<0.05$ for both, group A versus group N) (Figure 4). Treatment with rAAV-ASIL-5 notably reduced the level of ECP protein in plasma and BALF ( $P<0.05$ for both, group T versus group $A)$, though they were still higher than normal rats $(P<0.05$ for both, group $\mathrm{T}$ versus group $\mathrm{N})$. On the contrary, treatment with rAAV-EGFP had almost no effect on the level of ECP protein in plasma and BALF.

\section{Effect of rAAV-ASIL-5 on lung inflammation}

We lastly observed the effect of rAAV-ASIL-5 on lung inflammation via the lung histological sections under microscope (Figure 5). There was no accumulation or infiltration of eosinophils and few other inflammation cells in lung histological sections of normal rats. No visible bronchoconstriction was found either. In lung pathological sections of rat models of allergic asthma, severe inflammation was observed such as infiltration of eosinophils and lymphocytes, prolification of goblet cells, bronchial smooth muscle thickening and bronchoconstriction. With treatment with rAAV-ASIL-5, it showed mild inflammation, slight accumulation of eosinophils and lymphocytes, moderate bronchoconstriction in pathological sections of lung. However, the treatment of rAAV-EGFP had no effect on lung inflammation. We saw no apparent pathological abnormality in histological sections of heart, liver and kidney in all groups (figure not shown). 


\section{Discussion}

Previous studies have revealed that interfere of targeting IL-5 had significant results in suppression of eosinophils and airway hyper-reactivity in animal models of allergic asthma (15-17). Moreover, the anti-IL-5 therapy has shown prevention of eosinophils in clinic (18-20). All these researches suggested that blocking the function of IL-5 in vivo maybe an important strategy for developing a novel therapeutic approach to treat allergic asthma and other eosinophilic diseases.

The rAAV vector, which either integrates into the genome or remains in the nucleus as a stable episome, offers attractive advantages and may be one of the most promising gene vector for long-term therapy. In our past research, we succeeded to construct a rAAV vector-mediated anti-sense IL-5 gene (rAAV-ASIL-5). Furthermore, we founded this rAAV-ASIL-5 could efficiently suppress the expression of IL-5 mRNA and protein in $\mathrm{CD}_{4}{ }^{+} \mathrm{T}$ lymphocyte from rat models of allergic asthma in vitro (28).

On this base, we constructed a novel rAAV-ASIL-5 vector to carry the rat anti-sense IL-5 gene for animal experiment in vivo. The results of Southern-Blot and SDS-PAGE showed that the novel rAAV-ASIL-5 vector had properties of high-purity and high-titer. And we found that the novel rAAV-ASIL-5 vector could effectively infect BHK-21 cells in vitro (data not shown). We transfected allergic rats with the novel rAAV vector through tail vein injection twice and then observed its anti-IL-5 effect in vivo. As a result, we found that the expression of IL-5 protein in lung tissue and blood of rAAV-ASIL-5 pretreated rat decreased markedly when compared with allergic rats. It suggested that the novel rAAV-ASIL-5 vector suppressed expression of IL-5 protein in vivo.

Following, we observed the further anti-IL-5 effects of the novel rAAV-ASIL-5 vector. The counts of total white cells and eosinophils in blood and BALF were detected. It was found that the accumulation and infiltration of eosinophils in blood 
and airways of rAAV-ASIL-5 pretreated rats reduced remarkably, as compared with allergic rats. This result was concordant with many other researches $(16,17)$. It revealed the novel rAAV-ASIL-5 significantly inhibited eosinophils accumulation and infiltration in lung tissue and blood mainly via suppressing IL-5 expression.

In allergic asthma and many other eosinophilic diseases, ECP and MBP level are related to the activity of eosinophils and thought to reflect the severity of inflammation $(3,36-38)$. They may be used as one of the objectively adjusts and monitors of anti-inflammatory treatment in such diseases. Considering of these, we detected the expression of ECP protein in blood and BALF to observe the anti-eosinophil effect of the novel rAAV-ASIL-5 vector. It was found interestingly that the expression of ECP protein in blood and BALF were all decreased significantly with treatment with rAAV-ASIL-5, as compared with allergic rats. These findings revealed that our novel rAAV-ASIL-5 vector suppressed the accumulation and infiltration of eosinophils as well as the release of toxic granule proteins, such as ECP. It may play an important role of anti-inflammation in therapy of allergic asthma.

Finally, we observed through histological sections that the inflammation in airways of rAAV-ASIL-5 vector pretreated rats relieved when compared with allergic rats. All these results indicated that the novel rAAV-ASIL-5 expressed stablely and permanently in vivo, resulting in efficiently inhibition of IL-5 expression and eosinophils infiltration in lung and blood, as well as the secretion of toxic granule proteins. It may play a potential significant anti-inflammation role in the therapy of allergic asthma and other eosinophilic diseases.

Although AAV could infect many kinds of tissue cells, we found no apparent pathological damage to vital organs of rats in our study, such as heart, liver and kidney et al. It revealed that the rAAV vector had no pathological affect on vital organs of rats in short-term. Therefore, we concluded that the novel rAAV-ASIL-5 vector efficiently inhibited the expression of IL-5 and suppressed the accumulation of eosinophils in lung and blood in vivo.

In summary, this study showed that the delivery of rAAV-mediated anti-sense IL-5 
cDNA had the potential of preventing inflammation in allergic rats. These findings suggested the feasibility of rAAV for the gene therapy of allergic asthma and other eosinophilic diseases. No apparent adverse affects induced by rAAV injection were observed during the course of our study. Nevertheless, the further persistent anti-inflammation effects and long-term adverse effects need to be observed. The high level of expression from rAAV makes it attractive for human gene therapy. However, more experiments are needed to study the immunological aspects and the influence of the over-expression of the anti-sense-IL-5 gene on diverse biological processes before this approach is utilized clinically in the therapy of allergic asthma and other eosinophilic diseases. 


\section{References}

1. Malerba G, Pignatti PF. A review of asthma genetics: gene expression studies and recent candidates. J Appl Genet 2005; 46: 93-104.

2. Lee JJ, Dimina D, Macias MP, Ochkur SI, McGarry MP, O'Neill KR, Protheroe C, Pero R, Nguyen T, Cormier SA, Lenkiewicz E, Colbert D, Rinaldi L, Ackerman SJ, Irvin CG, Lee NA. Defining a link with asthma in mice congenitally deficient in eosinophils. Science 2004; 305: 1773-1776.

3. Walsh GM. Eosinophil granule proteins and their roles in disease. Curr Opin Hematol 2001; 8: 28-33.

4. Lampinen $\mathrm{M}$, Carlson $\mathrm{M}$, Håkansson LD, Venge $\mathrm{P}$. Cytokine-regulated accumulation of eosinophils in inflammatory disease. Allergy 2004; 59: 793-805.

5. Walsh GM, Al-Rabia M, Blaylock MG, Sexton DW, Duncan CJ, Lawrie A. Control of eosinophil toxicity in the lung. Curr Drug Targets Inflamm Allergy 2005; 4: 481-486.

6. Humbles AA, Lloyd CM, McMillan SJ, Friend DS, Xanthou G, McKenna EE, Ghiran S, Gerard NP, Yu C, Orkin SH, Gerard C. A critical role for eosinophils in allergic airways remodeling. Science 2004; 305: 1776-1779.

7. Pégorier S, Wagner LA, Gleich GJ, Pretolani M. Eosinophil-derived cationic proteins activate the synthesis of remodeling factors by airway epithelial cells. $J$ Immunol 2006; 177: 4861-4869.

8. Gleich GJ. Mechanisms of eosinophil-associated inflammation. J Allergy Clin Immunol 2000; 105: 651-663.

9. Sanderson CJ, Urwin D. Interleukin-5: a drug target for allergic diseases. Curr Opin Investig Drugs 2000; 1: 435-441.

10. Lampinen $\mathrm{M}$, Carlson $\mathrm{M}$, Håkansson LD, Venge $\mathrm{P}$. Cytokine-regulated accumulation of eosinophils in inflammatory disease. Allergy 2004; 59: 793-805.

11. Greenfeder S, Umland SP, Cuss FM, Chapman RW, Egan RW. Th2 cytokines and 
asthma. The role of interleukin-5 in allergic eosinophilic disease. Respir Res 2001; 2: $71-79$

12. Stirling RG, van Rensen EL, Barnes PJ, Chung KF. Interleukin-5 induces CD34(+) eosinophil progenitor mobilization and eosinophil CCR3 expression in asthma. Am $J$ Respir Crit Care Med 2001; 164: 1403-1409

13. Berro AI, Perry GA, Agrawal DK. Increased expression and activation of CD30 induce apoptosis in human blood eosinophils. J Immunol 2004; 173: 2174-2183.

14. Devos R, Plaetinck G, Cornelis S, Guisez Y, Van der Heyden J, Tavernier J. Interleukin-5 and its receptor: a drug target for eosinophilia associated with chronic allergic disease. J Leukoc Biol 1995; 57: 813-819.

15. Foster PS, Ming Y, Matthei KI, Young IG, Temelkovski J, Kumar RK. Dissociation of inflammatory and epithelial responses in a murine model of chronic asthma. Lab Invest 2000; 80: 655-662.

16. Karras JG, McGraw K, McKay RA, Cooper SR, Lerner D, Lu T, Walker C, Dean NM, Monia BP. Inhibition of antigen-induced eosinophilia and late phase airway hyperresponsiveness by an IL-5 antisense oligonucleotide in mouse models of asthma. J Immunol 2000; 164: 5409-5415.

17. Kumar RK, Herbert C, Webb DC, Li L, Foster PS. Effects of anti-cytokine therapy in a mouse model of chronic asthma. Am J Respir Crit Care Med 2004; 170: 1043-1048.

18. Leckie MJ, ten Brinke A, Khan J, Diamant Z, O'Connor BJ, Walls CM, Mathur AK, Cowley HC, Chung KF, Djukanovic R, Hansel TT, Holgate ST, Sterk PJ, Barnes PJ. Effects of an interleukin-5 blocking monoclonal antibody on eosinophils, airway hyper-reactivity, and the late asthmatic response. Lancet 2000; 356: 2144-2148.

19. Büttner C, Lun A, Splettstoesser T, Kunkel G, Renz H. Monoclonal anti-interleukin-5 treatment suppresses eosinophil but not T-cell functions. Eur Respir J 2003; 21: 799-803.

20. Kips JC, O'Connor BJ, Langley SJ, Woodcock A, Kerstjens HA, Postma DS, Danzig M, Cuss F, Pauwels RA. Effect of SCH55700, a humanized anti-human interleukin-5 antibody, in severe persistent asthma: a pilot study. Am J Respir Crit 
Care Med 2003; 167: 1655-1659.

21. Hildinger M, Auricchio A. Advances in AAV-mediated gene transfer for the treatment of inherited disorders. Eur J Hum Genet 2004; 12: 263-271.

22. Zhang PX, Fuleihan RL. Transfer of activation-dependent gene expression into $\mathrm{T}$ cell lines by recombinant adeno-associated virus. Gene Therapy 1999; 6: 182-189.

23. Hanazono Y, Brown KE, Handa A, Metzger ME, Heim D, Kurtzman GJ, Donahue RE, Dunbar CE. In vivo marking of rhesus monkey lymphocytes by adeno-associated viral vectors: Direct compatison with retroviral vectors. Blood 1999; 94: 2263-2270.

24. Rabinowitz JE, Rolling F, Li C, Conrath H, Xiao W, Xiao X, Samulski RJ. Cross-packaging of a single adeno-associated virus (AAV) type 2 vector genome into multiple AAV serotypes enables transduction with broad specificity. J Virol 2002; 76: 791-801.

25. Wu Z, Asokan A, Samulski RJ. Adeno-associated virus serotypes: vector toolkit for human gene therapy. Mol Ther 2006; 14: 316-27.

26. Xiao X, Li J, Samulski RJ. Production of high-titer recombinant adeno-associated virus vectors in the absence of helper adenovirus. J Virol 1998; 72: 2224-2232.

27. Warrington KH Jr, Herzog RW. Treatment of human disease by adeno-associated viral gene transfer. Hum Genet 2006; 119: 571-603.

28. GAO BA, XIONG WN, XU YJ, Zhang ZX, Cao Y, Tang YJ, Ye T, Du CL. Effects of recombinant adeno-virus vector carrying interleukin-5 antisense on the expression of interleukin-5 mRNA and protein in $\mathrm{CD}^{+} \mathrm{T}$ lymphocytes of asthmatic rats (Chinese). Chinese Journal of Internal Medicine 2006; 45: 298-301

29. $\mathrm{Wu} \mathrm{ZJ}, \mathrm{Wu} \mathrm{XB}$, Hou YD. Construction of a series of adeno-associated virus vectors and their expression of $\beta$ - galactosidase gene (Chinese). Chin J Virol 2000; 16: $1-6$.

30. Conway JE, Rhys CM, Zolotukhin I, Zolotukhin S, Muzyczka N, Hayward GS, Byrne BJ. High-titer recombinant adeno-associated virus production utilizing a recombinant herpes simplex virus type I vector expressing AAV-2 Rep and Cap. Gene Ther 1999; 6: 986-993.

31. Wu ZJ, Wu XB, Hou YD. Generation of a series of recombinant herpes simplex 
viruses which can provide replicating and packaging functions for recombinant adeno-associated virus (Chinese). Chinese J Exp Clin Virol 2002; 16: 74-78.

32. Auricchio A, Hildinger M, O'Connor E, Gao GP, Wilson JM. Isolation of highly infectious and pure adeno-associated virus type 2 vectors with a single-step gravity-flow column. Hum Gene Ther 2001; 12: 71-76.

33. Tang HF, Song YH, Chen JC, Chen JQ, Wang P. Upregulation of phosphodiesterase-4 in the lung of allergic rats. Am J Respir Crit Care Med. 2005; 171: $823-828$.

34. Renzi PM, Olivenstein R, Martin JG. Inflammatory Cell populations in the airways and parenchyma after antigen challenge in the rat. Am Rev Respir Dis 1993; 147: $967-974$.

35. Palmans E, Kips JC, Pauwels RA. Prolonged allergen exposure induces structural airway changes in sensitized rats. Am J Respir Crit Care Med 2000; 161: 627-635.

36. Venge P, Byström J, Carlson M, Hâkansson L, Karawacjzyk M, Peterson C, Sevéus L, Trulson A. Eosinophil cationic protein (ECP): molecular and biological properties and the use of ECP as a marker of eosinophil ctivation in disease. Clin Exp Allergy 1999; 29: 1172-1186.

37. Rosi E, Ronchi MC, Grazzini M, Duranti R, Scano G. Diagnostic accurancy of sputum outcomes in chronic stable asthma. Clin Exp Allery 2000; 30: 577-584.

38. in't Veen JC, Smits HH, Hiemstra PS, Zwinderman AE, Sterk PJ, Bel EH. Lung function and sputum characteristics of patients with severe asthma during an exacerbation by double-blind steroid withdrawal. Am J Resp Crit Care Med 1999; 160: 93-99. 


\section{Figure Legends}

Figure 1. Level of IL-5 protein in plasma and BALF in rats of normal control group (group N), asthmatic group (group A), rAAV-ASIL-5 treatment group (group T) and rAAV-EGFP negative control group (group C). Significant differences compared with group N shown as ${ }^{*} P<0.05$; Significant differences compared with group A shown as ${ }^{\#} P<0.05$; Significant differences compared with group $C$ shown as ${ }^{\$} P<0.05$.

Figure 2. Total cell count and eosinophil count in peripheral blood in rats of normal control group (group N), asthmatic group (group A), rAAV-ASIL-5 treatment group (group T) and rAAV-EGFP negative control group (group C). Significant differences compared with group $\mathrm{N}$ shown as ${ }^{*} P<0.05$; Significant differences compared with group A shown as ${ }^{\#} P<0.05$; Significant differences compared with group $C$ shown as $\$$ $<0.05$.

Figure 3. Total cell count and eosinophil count in BALF in rats of normal control group (group N), asthmatic group (group A), rAAV-ASIL-5 treatment group (group T) and rAAV-EGFP negative control group (group C). Significant differences compared with group $\mathrm{N}$ shown as ${ }^{*} \mathrm{P}<0.05$; Significant differences compared with group A shown as ${ }^{\#} P<0.05$; Significant differences compared with group $C$ shown as ${ }^{\$} P<0.05$.

Figure 4. Level of ECP protein in plasma and BALF in rats of normal control group (group N), asthmatic group (group A), rAAV-ASIL-5 treatment group (group T) and rAAV-EGFP negative control group (group C). Significant differences compared with group $\mathrm{N}$ shown as ${ }^{*} \mathrm{P}<0.05$; Significant differences compared with group A shown as ${ }^{\#} P<0.05$; Significant differences compared with group $\mathrm{C}$ shown as ${ }^{\$} P<0.05$.

Figure 5 HE stainings of lung in rats of normal control group (group N), asthmatic 
group (group A), rAAV-ASIL-5 treatment group (group T) and rAAV-EGFP negative control group (group C). (HE×200) 


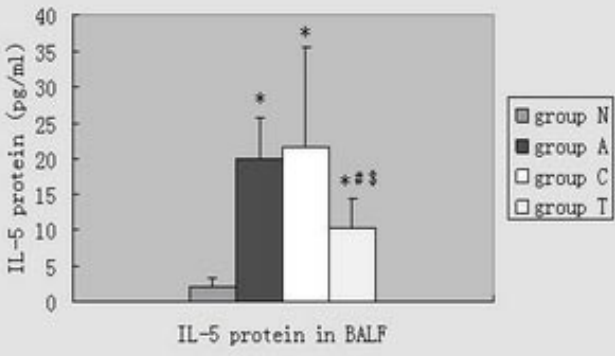




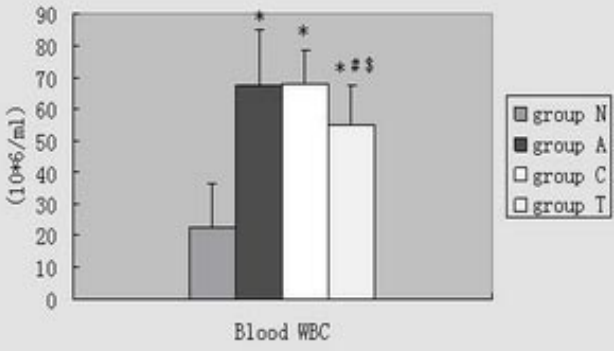




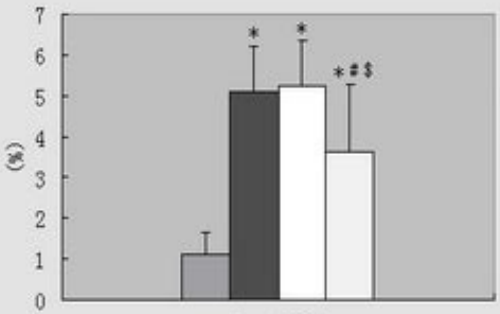

agroup N

a group A

a group C

$\square$ group $T$

Blood EOS 


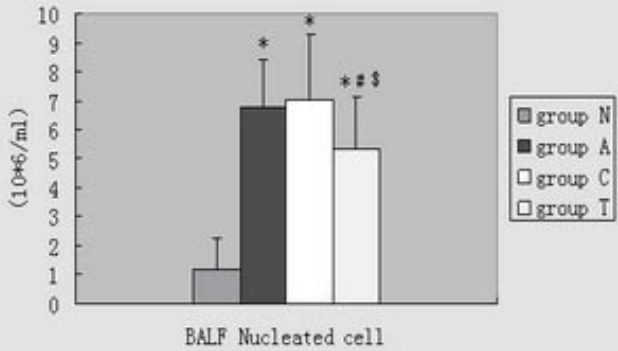




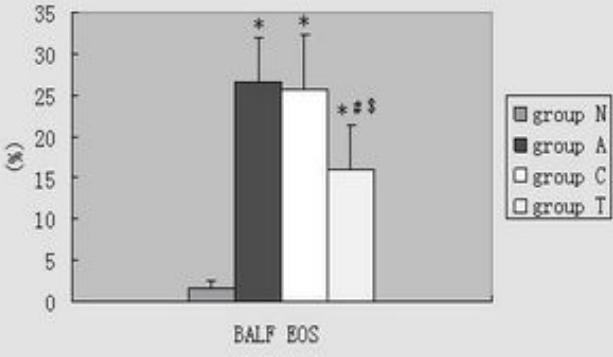




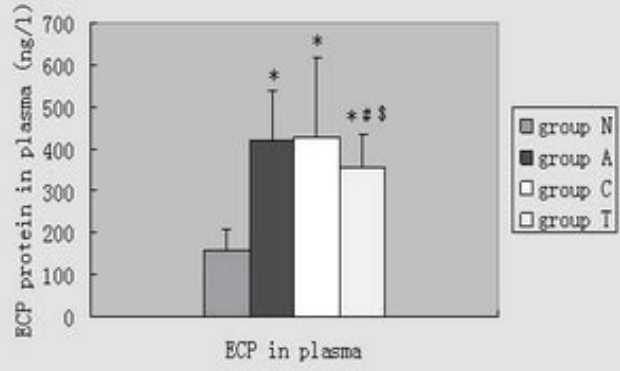




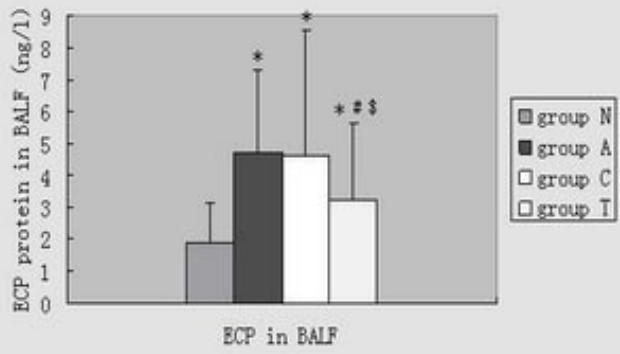




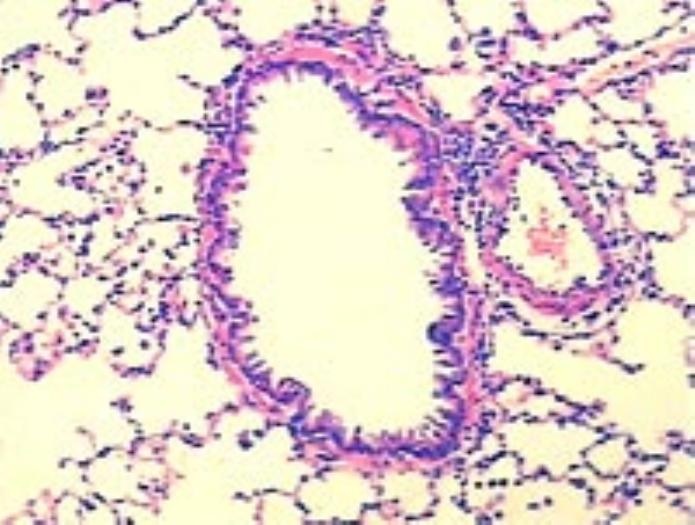




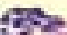

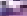
$2 \log ^{2}$
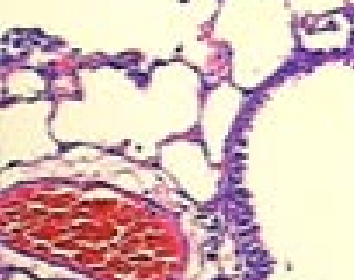

71

2 tons? Plats

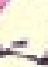

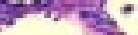
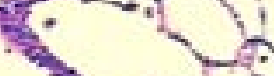

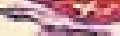
and
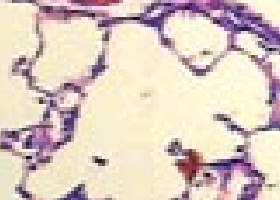
ind

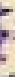

2. $=\frac{\pi}{4}$

th

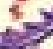
.
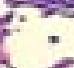

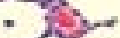

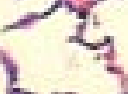

$+$

is
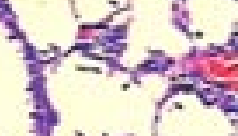

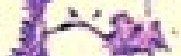

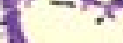

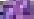

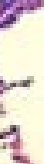

o

.<smiles>C1CCCC1</smiles> 